\title{
Discussion on Emotional Design of Preschool Children's Furniture
}

\author{
Weiguo Liu \\ Qingdao Technical College, 266555 China
}

\begin{abstract}
For physiological and psychological characteristics of pre-school children, this paper analyzes furniture design based on the need of pre-school children's furniture design, highlighting the design's emotion, safety, artistic, fun, functionality and furniture diversification to explore the new way of preschool children's furniture design.
\end{abstract}

Keywords- Preschool Children; Furniture Design; Emotional Design

\section{INTRODUCTION}

In China, because of traditional Chinese ideological background, children occupies a very important position in the family, and now they become a major consumer of today's society in family life, children's products market gradually expanded, with people's attention of the home life, the furniture start refinement, children's furniture is the same as furnishings in single apartment, the furniture industry has become a rising star in the field of design. According to the survey, $56 \%$ of households have purchased or have the desire to buy children's furniture, which has attracted the attention of many designers. At present, the development of children's furniture has gradually matured, there has been many kinds of brand such as FLEXA, MOKKI, A-OK, but these furniture are mostly designed for school-age children, pre-school children's furniture is very less on the market. Given the special nature of pre-school children's furniture and normative considerations for the market, small preschool age children, relatively immature mental, less accurately communicate with people to express their needs, pre-school children's furniture design is also a new topic worthy of our careful study.

\section{CONCEPT OF PRESCHOOL CHILDREN}

At present, China has no precise definition of "pre-school children", while preschool children (preschoolers), young children (infants) and early children (Early Childhood) have been extended for the same "pre-school children".

Child psychology works are by age, such as the neonatal period, infancy, childhood, adolescence, young adulthood, such as the arrangement of the system, which is taken by the majority of children work in infants' pharmacology system. In addition, it can also arranged by psychological development system, such as the development of a sense of perception, mind development, intellectual development, attention to the development, language development. There will be a mixed arrangement of the two child psychology which is a branch of psychological science. At the time of birth to early childhood, people can be divided into several stages: birth and newborn, Born 1 month; infancy: 1 month to 1 year old, the equivalent of suckling period; toddler hood: 1-2 years old; early childhood: 3-6 or 7 years old, the equivalent of early childhood, also known as pre-school. In the traditional sense, we will call pre-school stage before children officially enter primary school.

\section{CONCEPT OF PRESCHOOL CHILDREN' FURNITURE DESIGN}

In the dictionary of Chinese to English, the word "children's furniture" has not yet appeared, not to mention "pre-school children's furniture", but in the light of everyday life accumulation and experience, this paper will interpret "pre-school children's furniture" accommodating pre-school children's psychological characteristics and physiological characteristics, and also a class of equipment which can meet the need for children's life, playing, learning and exchanges, for children to sit, lie, or support and storage of goods and decorative features. It includes children's beds, children's tables, children's chairs, shelves, cabinets, children's wardrobe as well as toys. Pre-school children's furniture is by no means the scaled-down version or the cartoon version of adult furniture, but children's playing games props, learning aids, essential appliances in everyday life in the growth and development, in principle, it must be given complete planning and design in accordance with the age, gender, personality and other individual quote.

\section{THE IMPORTANCE OF EMOTIONAL DESIGN OF PRESCHOOL CHILDREN'S FURNITURE}

\section{A. Environmental Factors}

Pre-school children is a very important period for children's mental growth and development. Zhu Zhixian, our famous child psychologist said: "Innate are from the day after tomorrow, the day after tomorrow decides the innate." This means that the environment determines the direction and content of the psychological development of children. Preschool is an important stage for child character forming. In ancient China, "Meng Mu moved three" story also fully proved this point. Children's furniture which is closely related to children's living environment, also plays a very important role in child psychology, child emotional formation. Therefore, we should now focus on children's furniture emotional design. 


\section{B. pre-school children demand factors}

Children's psychological research proves, since birth child has his emotions and feelings, children older than three years have their own ideas and requirements, we cannot ignore their existence because of their age, on the contrary, they are furniture of users, they are people who have the final say. Perhaps some children cannot properly express their feelings, unable to fully communicate with a designer, but as a user of furniture, we should respect their needs, focusing on children's mental age characteristics in the design, design furniture suitable for pre-school children so as to be more conducive to the healthy growth of pre-school children.

\section{C. market demand factors}

With our constantly updated furniture design concept, adult furniture has now matured which can form a mature industry chain structure from creating to design to manufacturing. But in terms of children's furniture, although it also gradually embarked mature, the size reduction and color change of the adult furniture also exists, especially preschool children's furniture design is still not system on the market piecemeal products, and there is homogeneity, similar shape and the problem of irrational industrial structure. As children's product, this should reveal a colorful, blossom, personalized strong situation, but in the market of children's furniture, generally not only similar in appearance, but also the monotony of cartoon images or layout of bright colors, the design is just simple analysis of the child's immature psychological, without deepening the process of psychological change. In the structure of children's furniture, furniture used by children under the age of $7-14$ years old accounts for most proportion, while children's furniture is rare for other age, especially preschoolers. Pre-school children are very different in psychologically and physiologically with older children, the furniture features are bound to be distinguished, which should occupy a certain share of the children's furniture market.

\section{The Principle of EMotional Design of PRESCHOOL CHILDREN'S FURNITURE}

Focus on the principles of psychology health training: children are in the most rapid period of psychological development during pre-school, which is crucial to a child's life growth and development, should pay attention to children's mental health education in furniture design. Furniture design should contain scientific justification, natural image, human good and the beautiful, and can provide play areas and activities world.

Focus on smart development principles: the size of the child abstract thinking and problem-solving ability comes from the child's intelligence, it is common decision by congenital and acquired factors. But for the average person, acquired factors play a decisive role. Congenital factor is determined by genetics, acquired factor is determined by the environment, the environment can be divided into aspects of the natural environment, family environment, and education environment, ecological and cultural environment. Furniture is the main factor in the composition of these environments, in the design, we want to promote the development of preschool children through furniture design techniques such as furniture shape, color, decoration, versatility to observe the development of intelligence, the development of thinking skills and promote their emotional intelligence and creative ability.

Pay attention to the principles of good behavior habits: Related scientific research proved that the sensitive period of developing habits was earlier than that of the intellectual development. The rapid development of intelligence for the child is in early childhood, and habits are formed from infancy. After the child is born, they gradually formed a diet, living, thinking and other habits, which imply a budding of moral behavior and play an important role in children's development. Thus, in furniture design, we should give full consideration to the child's good behavior training and guidance.

Focus on the principles of overall quality of its personal training humanities and arts: good environmental design and furniture design cannot only create a good living environment, but also please the child's mind and cultivate the child's temperament, also ignited the content of moral education such as thinking and understanding, awareness and education are produced in the ear rendered witnessed among art furniture.

Focus on the principles of child personality development training: under normal circumstances, personalized products depends on the individual user groups. As preschoolers, the majority of people believe that subjective consciousness is not strong, and it doesn't form their own aesthetic values, does not have an independent personality. In fact, this is not right. Genetic, personality, gender and family environment factors of each child will be different, because of this, their interest, favorite furniture will be different, and children will choose the product close to their own personality and characteristics. Thus, in the design, to analyze their personality according to the development characteristics of children is necessary, starting from its own personality to make diversified design of furniture, so that the design has a distinct personality so as to meet the individual needs of preschool children.

\section{The Problem to be Solved in Emotional Design OF PRE-SCHOOL CHILDREN'S FURNITURE}

Pre-school children's furniture design is not just for the room's looking good, practical, but also gives full consideration to the child's physiological and psychological needs, to fully meet the child's emotional needs. At the same time, doing these in the design must also resolve well the following three questions:

Security issues: physiological characteristics of pre-school children decides that they are more likely to suffer external injuries than the general age, their physical and psychological are immature, not fully understanding of things. Thus, in design, it should be filled with safety in the details of the deal to make ease use of. To effectively address the safety, the first is non-toxic in the choice of materials, and try to choose lightweight materials or extremely heavy material, and glass materials with caution. Second, we must 
pay attention to the safety of the shape, the appearance structure should be no sharp sleek shape and try to avoid furniture set, and furniture door design prominence to adopt damper design, less parts, especially the small parts should be avoided. Finally, not too much in color, too brilliant would cause color pollution. The best use of red, yellow, and blue must color simplistic as far as possible.

Ergonomic problems: when designing children's furniture, it should be noted that engineering principles should be consistent with the child's body on the size of children's furniture, the size cooperating with the user's height, in addition, taking into account the age and size of design objects made products meet their physiological dimensions, so that not only let the children feel comfortable in the use, benefit their growth, it will muster positive joyful mood on emotion, form a good person ergonomic dialogue.

Functional problems: functional refers use value of furniture. Aiming to the demand of preschoolers, use appearance, color and technology to realize. According to pre-school children's characteristics such as fast physical growth and development, lively, full of fantasy, strong ability to explore and the diverse needs and other characteristics, functional of furniture should be toward diversification, exchange, integration and growth-oriented development.

\section{CONCLUSION}

In short, the study of pre-school children's emotional furniture design can create a good psychological and physiological development for children, promote the healthy development of children in all aspects so as to protect the healthy growth of minors and to create a better tomorrow for the community.

\section{REFERENCES}

[1] LEXA: new fashion of children's room design.

[2] Zhang M. 120 ask of Psychology and Education of Preschool Child. Shanghai Popular Science Press.

[3] Pu C. Study on basic theory of Zhu Zhixian child psychology. Journal of Longdong College.

[4] Kang L. Analysis on the diversification of children's furniture design. VIP News

[5] Liu C. Research on Trends and Key Technologies of Small Satellites [J]. International Journal of Science, 2014, 1(2): 38-42.

[6] Zeng C. Children's furniture should be consistent with the physical and psychological characteristics of Children [J]. Guizhou University of Technology (Natural Science). 